\title{
Natural Log Transformed Cmax
}

National Cancer Institute

\section{Source}

National Cancer Institute. Natural Log Transformed Cmax. NCI Thesaurus. Code C161415.

The natural log transformed maximum concentration occurring at Tmax. 